\title{
Some Factors Affecting the Dimensional Stability of the Silver-Tin-(Copper-Zinc) Amalgams*
}

\author{
J. A. Mitchell, ${ }^{1}$ I. C. Schoonover, George Dickson, and H. C. Vacher
}

\begin{abstract}
An investigation of the X-ray diffraction characteristics and of the dimensional changes of silver-tin-(copper-zinc) amalgams during and after their hardening period indicated that uncombined mercury was present in the amalgams after the initial solidification and that this uncombined mercury disappeared during the period when greatest dimensional changes occur. On the basis of the data obtained, it is postulated that the expansion during the hardening of amalgam results from diffusion of uncombined mercury throughout the material; the subsequent shrinkage then results from combination of this mercury with existing phases or with residual alloy.
\end{abstract}

\section{Introduction}

Although an enormous amount of experimental work has been done on the silver-tin-(copper-zinc $)^{2}$ amalgams $[1,2,3,4,5,6],{ }^{3}$ no mechanism has been proposed that will satisfactorily explain the initial contraction, subsequent expansion, and final contraction that occur during the first $24 \mathrm{hr}$ after amalgamation. Various investigators have attempted to explain these changes in terms of mercury content of the amalgam system. Their difficulty may have resulted from the failure to differentiate between total mercury and combined mercury in this system. It is probable that in the hardening of the heterogeneous mass not all the mercury is in the combined form. Chemical analysis of the amalgam would not distinguish between combined and uncombined mercury. Furthermore, photomicrographic evidence [7] indicates that the rate of attack on the alloy particles by mercury may vary widely, depending upon the conditions under which the specimen was prepared. The possible diffusion of this mercury, if it is present, and its subsequent reactions with the alloy may account for the dimensional changes observed in the hardened amalgam.

With this in mind, the investigation was undertaken to determine (1) whether uncombined mercury was present after the amalgam had hardened, (2) whether the uncombined mercury, if present, continued to take part in any reaction, and (3) whether the dimensional changes that occur in hardened amalgam could be correlated with this reaction.

\section{Experimental Approach and Procedures}

X-ray diffraction methods cannot be used to detect the presence of free or uncombined mercury in an amalgam at room temperature because the mercury,

\footnotetext{
*A dissertation submitted to the faculty of the Graduate School, Georgetown University, in partial fulfillment of the requirements for the degree of Master

1 Guest worker at the National Bureau of Standards, and member of Dental
1 .

Corps, Department of the Navy.
2 The chemical symbols Ag-Sn- $(\mathrm{Cu}-\mathrm{Zn})$ are used hereafter. Copper-zine is placed in parentheses because these elements are not always present in the abovementioned amalgams.

mentioned amalgams.
${ }^{3}$ Figures in brackets indicate the literature references at the end of this paper
}

being a liquid at this temperature, does not have a crystalline structure and does not give an X-ray diffraction pattern. However, if the mercury is chilled below its solidification point, typical lines representing mercury are detected by diffraction methods. Therefore, if uncombined mercury is present in amalgam immediately after hardening, it should be possible to determine its presence by X-ray investigation of amalgam specimens held below the freezing temperature of mercury. Furthermore, it should be possible to study the rate of disappearance of the uncombined mercury with time by periodic examination of the specimen at temperatures below the freezing point of mercury.

X-ray diffraction patterns of the amalgams at low temperatures were obtained from specimens that were manually condensed, using standard dental procedures, in a stainless-steel mold and specimenholder combination (fig. 1). Immediately after condensation, the amalgam specimens were frozen by introducing liquid nitrogen into the chamber beneath the specimen. An iron-constantan thermocouple was inserted in the specimen holder, near the specimen for temperature determination.

Three commercial amalgam alloys were used in the investigation. Amalgams were produced by triturating the alloys with mercury in a mechanical amalgamator, using the mercury-alloy ratio of 2 to 3 for alloys 1 and 2, and a ratio of 2 to 3.6 for alloy 3 .

A high-angle spectrometer goniometer [8] was used to obtain chart records of the copper K-alpha diffraction. The diffraction unit was operated at $35 \mathrm{kv}$ and a tube current of $20 \mathrm{ma}$. The angular speed of the scanning arm was $1 \mathrm{deg} / \mathrm{min}$, and the chart speed was $1 / 2$ in. $/ \mathrm{min}$

$\mathrm{X}$-ray diffraction characteristics were obtained with the specimen and its holder maintained at the constant reduced temperature $\left(-125^{\circ} \mathrm{C}\right)$ during the making of chart records in a $2 \theta$ range of 80 to $28 \mathrm{deg}$. The specimen was then warmed to mouth temperature $\left(37^{\circ} \mathrm{C}\right)$ and aged at that temperature until the next low-temperature diffraction-chart recording was made.

The X-ray diffraction technics described above were used also to determine the effect of addition of 

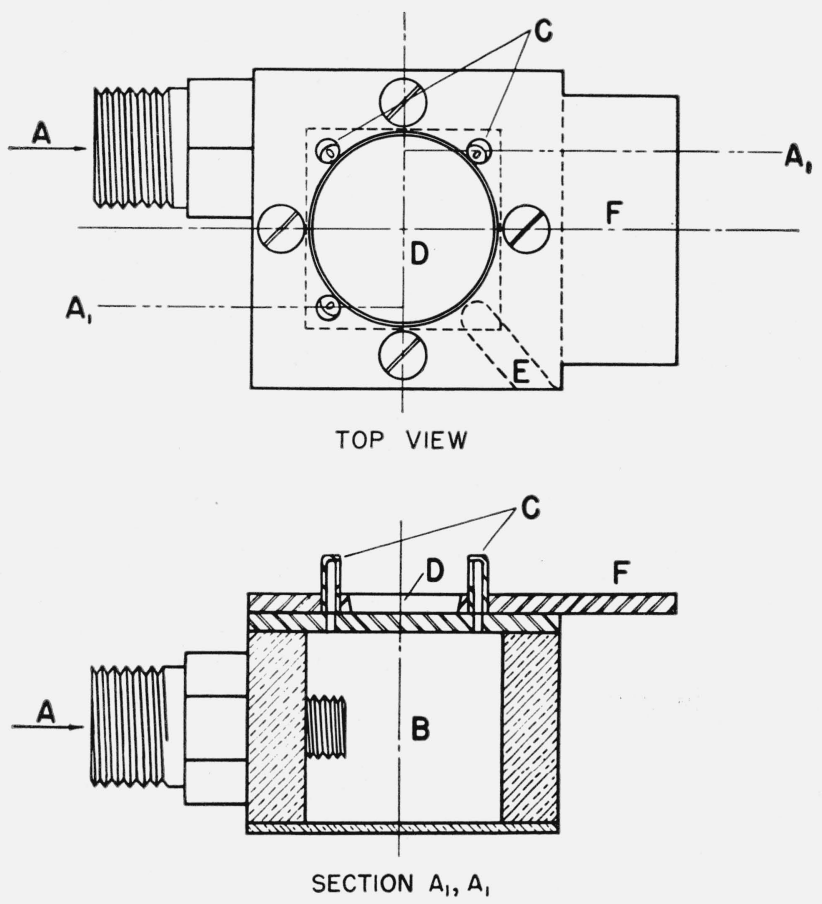

Figure 1. Amalgam mold and specimen holder for lowtemperature $X$-ray diffraction studies.

Holder enclosed in a cylindrical box. Specimen retained in holder and alternately cooled to $-125^{\circ} \mathrm{C}$ by liquid nitrogen and warmed to $37^{\circ} \mathrm{C}$ by a wirewound resistor regulated with a variable autotransformer.

A, Liquid nitrogen intake; B, liquid-nitrogen chamber; C, jets; D, specimen; $\mathrm{E}$, thermocouple rest; $\mathrm{F}$, arm fastened to goniometer shaft.
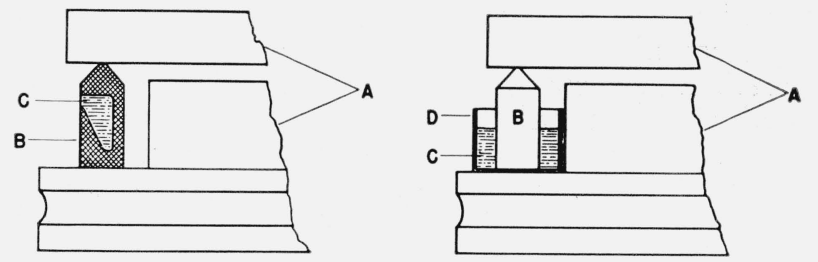

Figure 2. Measurement of dimensional change of fully hardened amalgam specimens after addition of mercury.

Mercury added internally and externally.

A, Dental interferometer; B, specimen; C, mercury; D, iron cup.

mercury to fully hardened amalgam specimens. Seven-day-old specimens were immersed in mercury for $12 \mathrm{hr}$, removed and cooled to $-125^{\circ} \mathrm{C}$, and examined by X-ray diffraction. The specimens were kept at $37^{\circ} \mathrm{C}$ during the next $24 \mathrm{hr}$, except for periodic cooling to $-125^{\circ} \mathrm{C}$ while the diffraction charts were made.

To examine the effect of uncombined mercury on dimensional changes of hardened amalgam, mercury was added both externally and internally to hardened amalgam specimens, and their dimensional changes were measured by means of dental interferometers [9], (fig. 2). Hardened specimens of amalgam in iron cups were positioned in interferometers. Mercury was added to the cups, and the dimensional changes were observed over a period of 15 days on two series of specimens held at $21^{\circ}$ and $37^{\circ} \mathrm{C}$, respectively. In other experiments a small hole was drilled in the specimen and mercury injected into the hole in the amalgam by means of a hypodermic syringe after the specimens had been positioned in the interferometers. Dimensional changes were then observed over a period of 15 days. Temperatures were maintained by constant-temperature air baths.

In two of the above experiments the supply of mercury was removed from contact with the specimens after the period of 15 days, and dimensional changes were observed for an additional period of 26 days.

To obtain information on the effect of temperature on the reactions occurring during the hardening of the dental amalgams, dimensional changes of amalgams prepared and observed at various temperatures were also determined interferometrically.

\section{Results}

\subsection{X-ray Diffraction Examination of the Ag-Sn-(Cu-Zn) Amalgams}

As shown in table 1, one of the three commercial amalgam alloys used in the investigation was a silver-tin-zinc alloy, one a silver-tin-copper-zinc, and the other a silver-tin-copper alloy. Upon examining their X-ray diffraction patterns (fig. 3), it is evident that the variation in copper and zinc content has little effect on the diffraction patterns as the position of the principal peaks are identical in all three charts.

TABLE 1. Chemical composition of alloys investigated

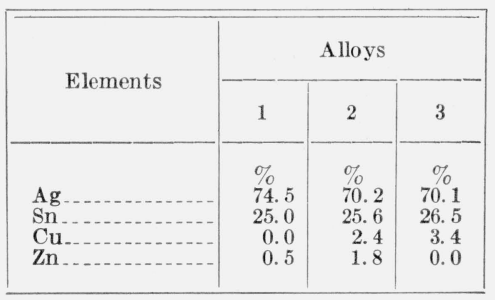

$\mathrm{X}$-ray diffraction charts of pure mercury at $-125^{\circ}$ $\mathrm{C}$ show a number of well-defined peaks (fig. 4, a). A specimen of amalgam containing the Ag-Sn-Cu$\mathrm{Zn}$ alloy was made at room temperature $\left(25^{\circ} \mathrm{C}\right)$, placed in position, and its X-ray pattern determined at $-125^{\circ} \mathrm{C} 5 \mathrm{~min}$ after the start of $\operatorname{mix}$ (fig 4 (b). The characteristic peaks of the uncombined mercury can be seen as represented by the solid-black areas. As the specimen is aged through longer periods of time at $37^{\circ} \mathrm{C}$, the characteristic peaks of the uncombined mercury tend to disappear, and after $6 \mathrm{hr}$ they are scarcely detectable (fig. 4 (c), and fig. 5). This time period corresponds generally to the period during which significant expansion and contraction are commonly observed. Simultaneously with this reduction in uncombined mercury, there is a disap- 

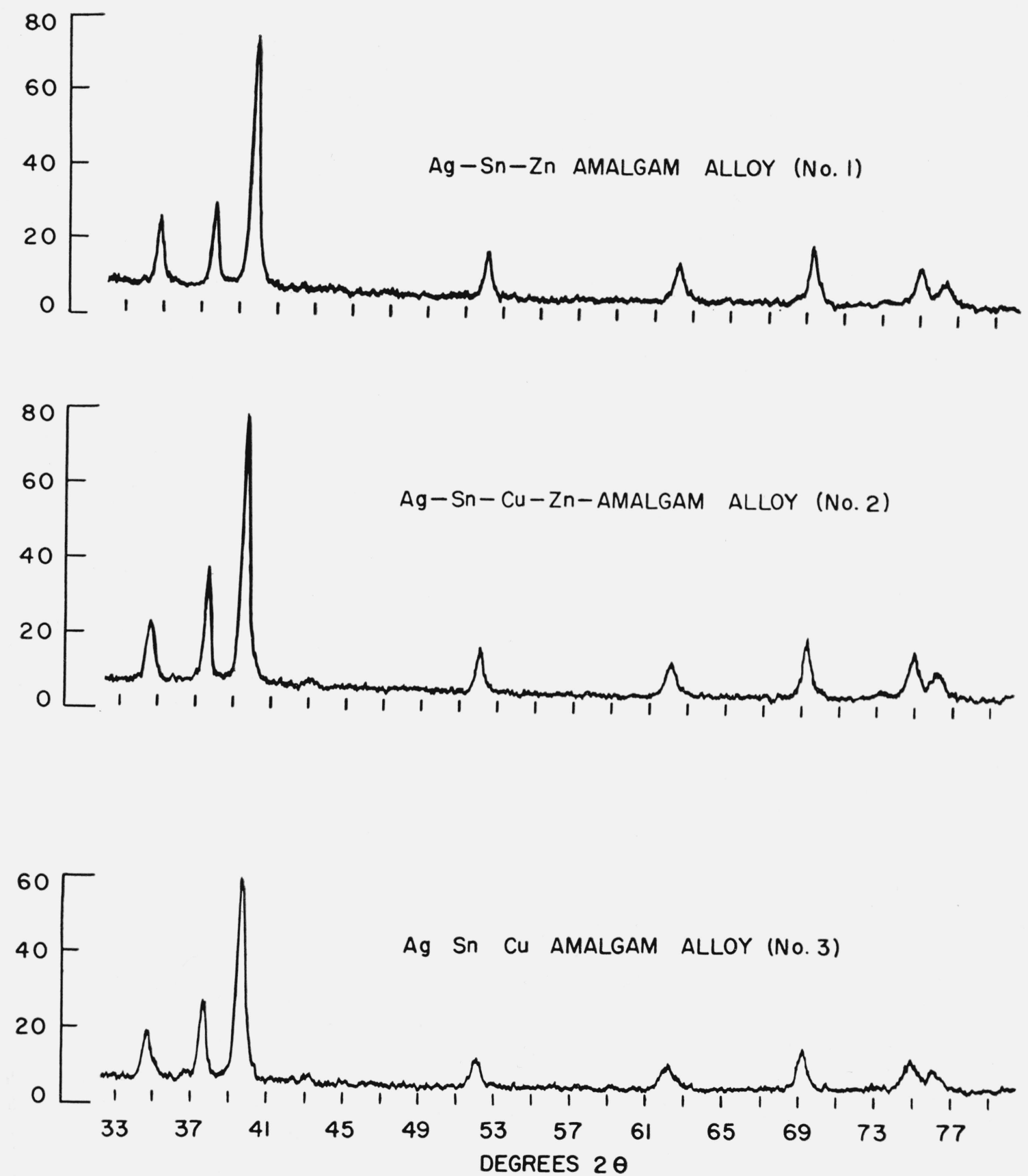

Figure 3. X-ray diffraction charts (with a scale factor of 4 ) made at $25^{\circ} \mathrm{C}$.

The similarity of the charts for the three alloys indicates that none of the lines shown are dependent upon the copper or zinc content of the
lloys. 

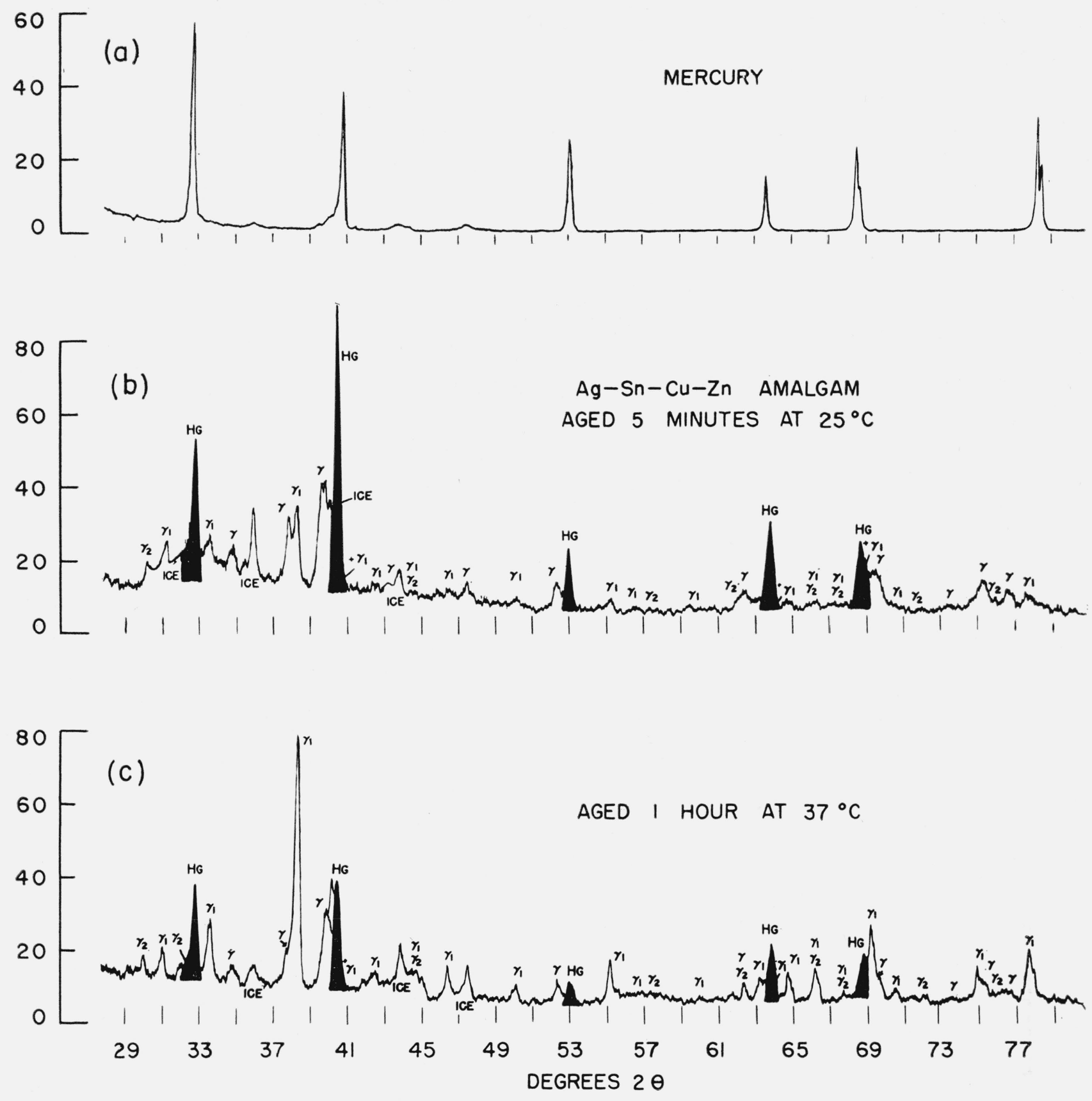

FIGURE 4. X-ray diffraction charts made at $-125^{\circ} \mathrm{C}$.

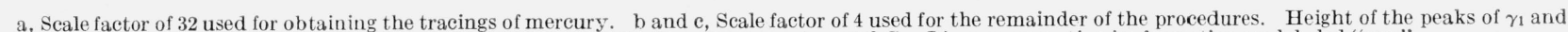
$\gamma_{2}$ lines hidden by the mercury lines were determined by X-ray diffraction charts made at $37^{\circ}$ C. Lines representing ice formation are labeled "ICE." 

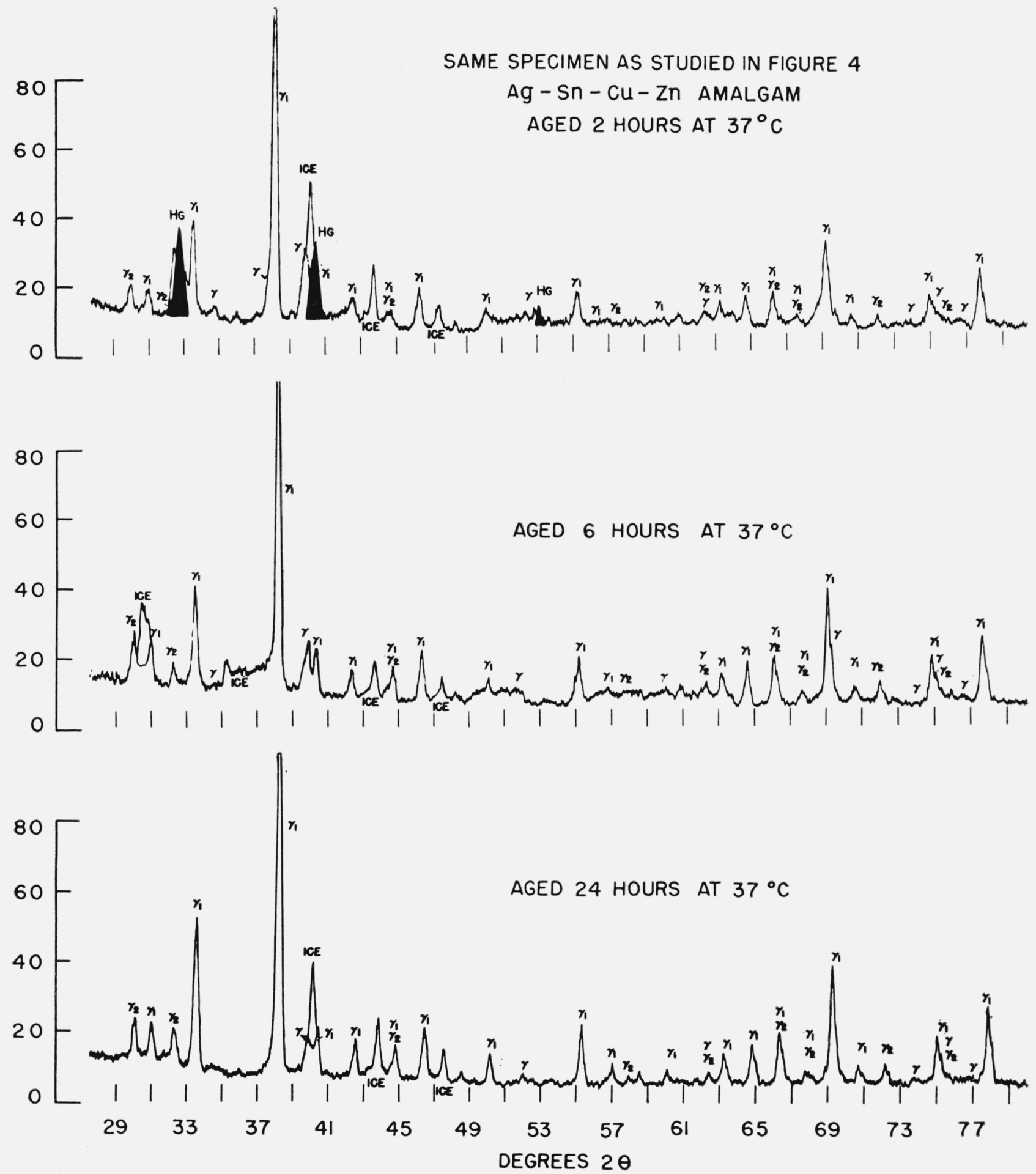

Figure 5. X-ray diffraction charts made at $-125^{\circ} \mathrm{C}$.

(See legend for fig. 4, b and c) 

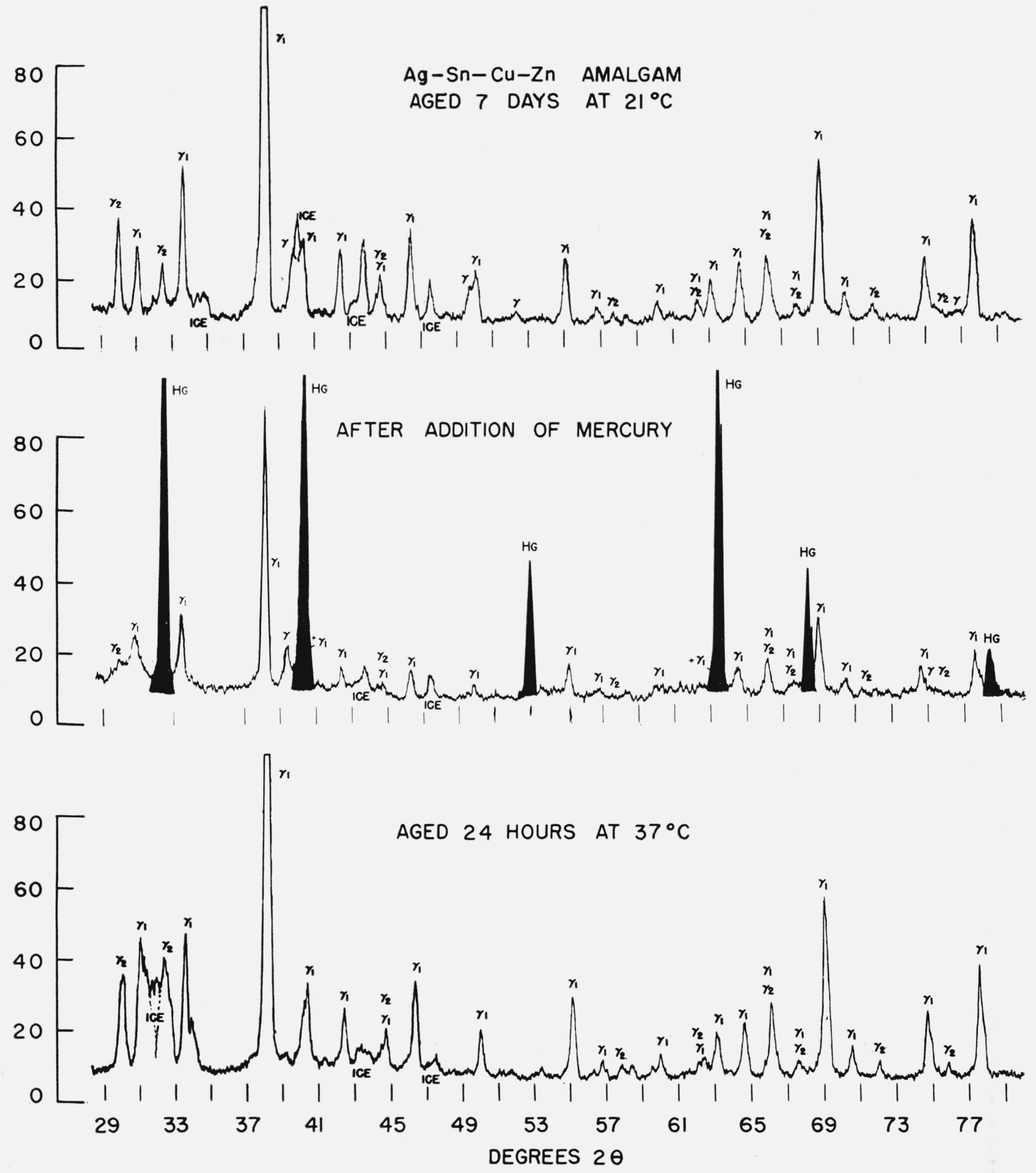

Figure 6. X-ray diffraction charts made at $-125^{\circ} \mathrm{C}$.

(See legend for fig. $4, \mathrm{~b}$ and $\mathrm{c}$ ) 
pearance of the lines representing the original alloy $(\gamma)^{4}$ and an increase in the $\gamma_{1}$ and $\gamma_{2}$ phases (fig. 4 (b) and (c), and fig. 5). This indicates that the disappearance of the free mercury lines was through combination of the mercury with the alloy to form mercury compounds.

X-ray diffraction charts made periodically at reduced temperatures after the addition of mercury to fully hardened amalgam showed intense mercury lines in the specimens observed immediately after removal from the mercury bath (fig. 6). These mercury lines were not detected after the specimens had been held at $37^{\circ} \mathrm{C}$ for $24 \mathrm{hr}$ or at $21^{\circ} \mathrm{C}$ for 3 days. In figure 6 it can be seen that mercury on the surface of the specimens reduces the intensity of the lines representing the original alloy and $\gamma_{1}$ and $\gamma_{2}$ phases. After aging for $24 \mathrm{hr}$, the mercury has combined with the original alloy as indicated by the absence of $\gamma$ and uncombined mercury lines.

Consideration was given to the possibility that the intermediate phases in the $\mathrm{Ag}-\mathrm{Sn}-(\mathrm{Cu}-\mathrm{Zn})$ amalgams might have a higher mercury solubility at room temperature than at temperatures below the freezing point of mercury. Under such conditions, crystalline mercury at low temperatures might be formed by rejection from a solid solution existing at room temperature. However, the disappearance of the lines representing uncombined mercury indicates that such a rejection does not occur to a significant extent if at all.

\subsection{Dimensional Change Determinations of the Ag-Sn-(Cu-Zn) Amalgams}

The addition of mercury to the hardened specimens produced large expansions, whether the mercury was added internally or externally (fig. 7). Specimens maintained at $37^{\circ} \mathrm{C}$ expanded much more than those maintained at $21^{\circ} \mathrm{C}$. The great difference in expansion between the two specimens placed in mercury baths at $37^{\circ} \mathrm{C}$ may result from imperfections or other variations in the individual specimens that affect the rate of diffusion of mercury into the amalgam. Only very slight dimensional changes occurred after removal of the supply of excess mercury from hardened specimens (fig. 8).

Amalgam specimens prepared and maintained at either $21^{\circ}$ or $37^{\circ} \mathrm{C}$ showed a rapid initial contraction, followed by some expansion during the first 24-hr period. Average values for dimensional changes are plotted against time in figure 9, 10, and 11 . $\mathrm{Ag}-\mathrm{Sn}-\mathrm{Zn}$ amalgams prepared at $21^{\circ} \mathrm{C}$ and maintained at $37^{\circ} \mathrm{C}$ gave an over-all shrinkage, whereas those prepared and maintained at $21^{\circ} \mathrm{C}$ gave an over-all expansion (fig. 9 and table 2). Ag-Sn-Cu-Zn amalgams prepared and maintained at $37^{\circ} \mathrm{C}$ also had greater initial contraction, lower maximum expansion and greater over-all contraction than those prepared and maintained at $21{ }^{\circ} \mathrm{C}$ (fig. 10 and table 2). $\mathrm{Ag}-\mathrm{Sn}-\mathrm{Cu}-\mathrm{Zn}$ amalgams initially observed at $21^{\circ} \mathrm{C}$ and then subjected to a temperature increase to $37^{\circ} \mathrm{C}$ shrank more than those maintained at $21^{\circ} \mathrm{C}$

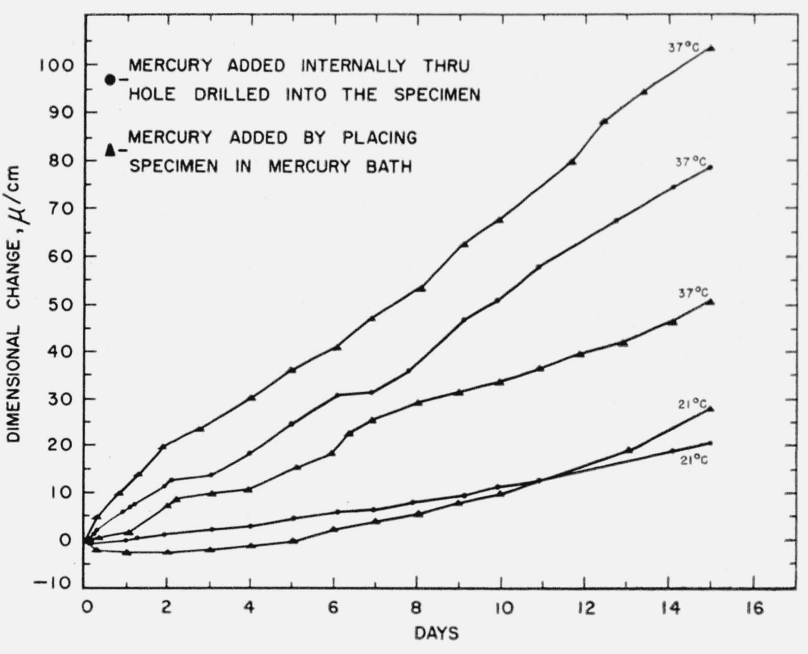

Figure 7. Dimensional changes in Ag-Sn-Cu-Zn amalgam (alloy 2) resulting from addition of mercury.

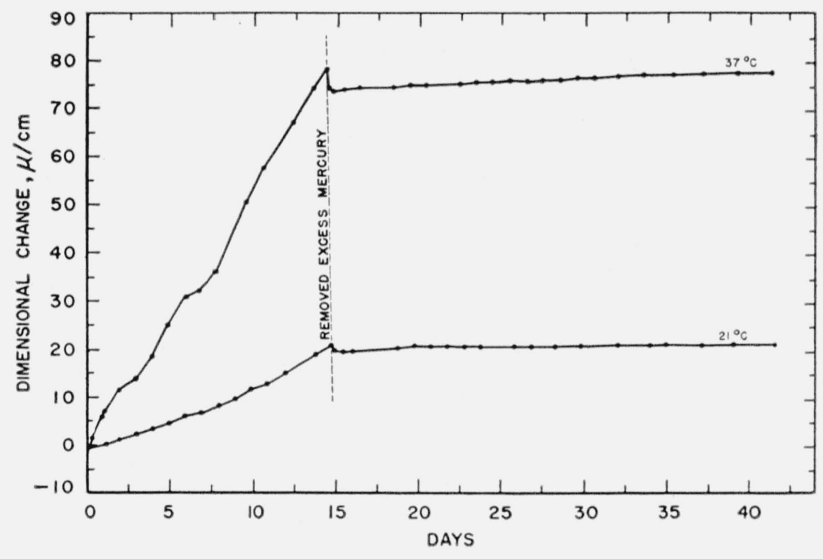

Figure 8. Dimensional changes of Ag-Sn-Cu-Zn amalgam (alloy 2) resulting from addition and removal of mercury.

0 days, mercury added internally through hole drilled into specimen; 15 days, excess mercury removed from hole drilled into specimen.

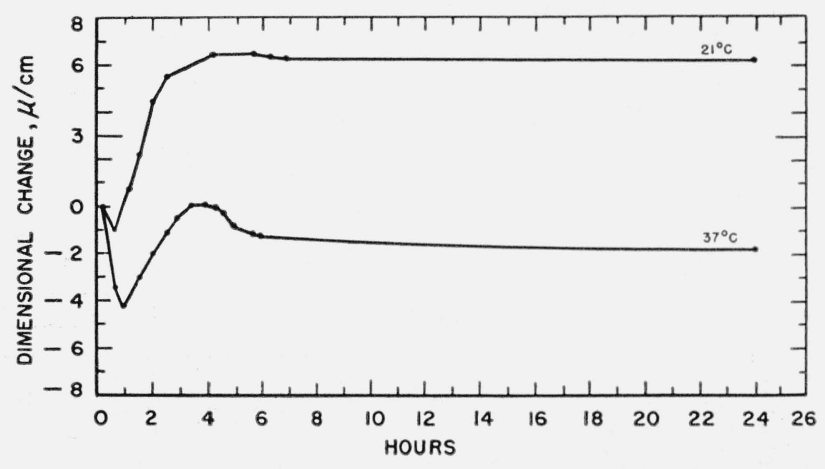

Figure 9. Comparison of dimensional changes of $\mathrm{Ag}-\mathrm{Sn}-\mathrm{Zn}$ amalgam (alloy 1 ) at $21^{\circ} \mathrm{C}$ and at $37^{\circ} \mathrm{C}$.

Specimens prepared at $21^{\circ} \mathrm{C}$. 


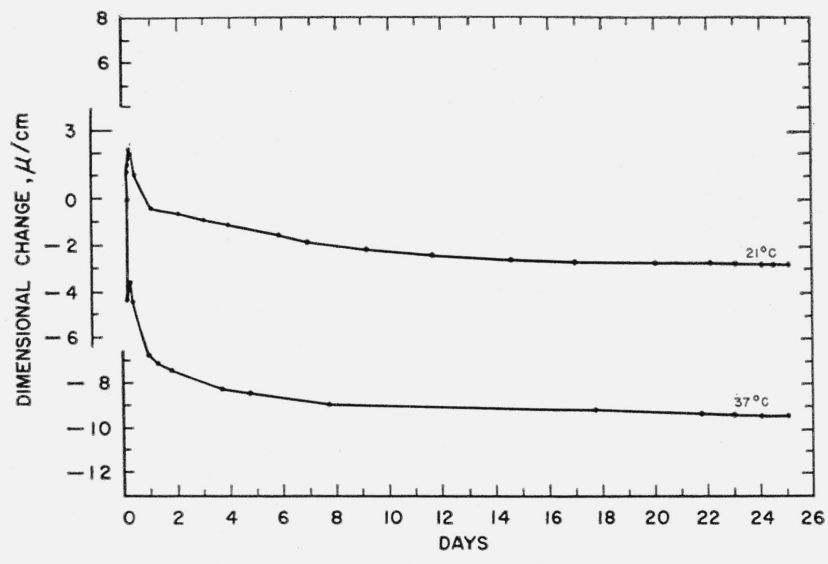

FIgURE 10. Cemparison of dimensional changes of Ag-SnCu-Zn amalgam (alloy 2) at $21^{\circ} C$ and at $37^{\circ} C$.

Specimens prepared at $21^{\circ} \mathrm{C}$ and at $37^{\circ} \mathrm{C}$, respectively.

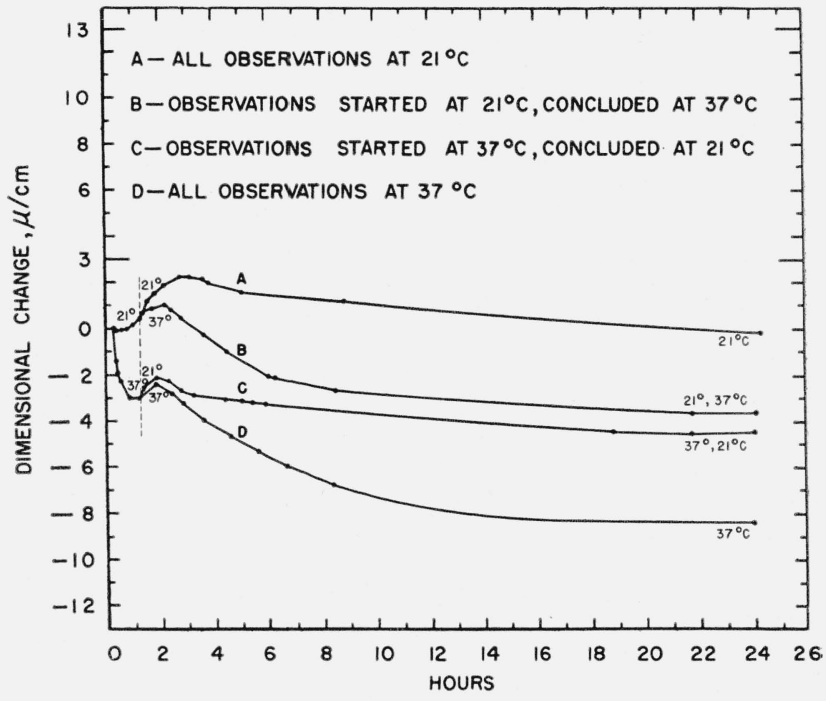

Figure 11. Comparison of dimensional changes of Ag-Sn$\mathrm{Cu}-\mathrm{Zn}$ amalgam (alloy 2) at $21^{\circ} \mathrm{C}$ and at $37^{\circ} \mathrm{C}$.

Specimens prepared at $21^{\circ} \mathrm{C}$.

TABLE 2. Dimensional changes and their standard errors for $\mathrm{Ag}-\mathrm{Sn}-(\mathrm{Cu}-\mathrm{Zn})$ amalgams at $21^{\circ}$ and $37^{\circ} \mathrm{C}$

\begin{tabular}{|c|c|c|c|c|c|c|c|}
\hline \multirow{2}{*}{ Alloy } & \multirow{2}{*}{$\begin{array}{l}\text { Temperature of } \\
\text { observation a }\end{array}$} & \multirow{2}{*}{$\begin{array}{c}\text { Number } \\
\text { of speci- } \\
\text { mens } \\
\text { observed }\end{array}$} & \multicolumn{3}{|c|}{$\begin{array}{l}\text { Fiducial observation } 15 \text { min after start } \\
\text { of mix }\end{array}$} & \multirow{2}{*}{$\begin{array}{c}\text { Fiducial } \\
\text { observation } \\
10 \text { min after } \\
\text { start of mix } \\
\text { (change } 24 \\
\text { hr) }\end{array}$} & \multirow{2}{*}{ Typical curves } \\
\hline & & & $\begin{array}{l}\text { Initial } \\
\text { contraction }\end{array}$ & $\begin{array}{l}\text { Maximum } \\
\text { expansion }\end{array}$ & $\begin{array}{l}\text { Change in } \\
24 \mathrm{hr}\end{array}$ & & \\
\hline \multirow[t]{2}{*}{1} & $\begin{array}{l}{ }^{\circ} \mathrm{C} \\
21 \\
37\end{array}$ & $\begin{array}{l}7 \\
8\end{array}$ & $\begin{array}{c}\mu / \mathrm{cm} \\
-1.3 \pm 0.1 \\
-4.1+0.4\end{array}$ & $\begin{aligned} & \mu / \mathrm{cm} \\
+ & 7.0 \pm 0.3 \\
+ & 0.0 \pm 0.3\end{aligned}$ & $\begin{array}{c}\mu / \mathrm{cm} \\
+6.2 \pm 0.3 \\
-2.1 \pm 0.3\end{array}$ & $\begin{array}{c}\mu / \mathrm{sm} \\
+4.3 \pm 0.5 \\
-6.2+0.4\end{array}$ & \multirow[t]{2}{*}{ Figure 9.} \\
\hline & Difference... & & $2.8 \pm 0.5$ & $7.0 \pm 0.4$ & $8.3 \pm 0.5$ & $10.5 \pm 0.6$ & \\
\hline \multirow[t]{2}{*}{ b 2} & $\begin{array}{r}21 \\
\text { c } 37\end{array}$ & $\begin{array}{l}4 \\
4\end{array}$ & $\begin{array}{l}-0.3 \pm 0.05 \\
-4.2 \pm 0.6\end{array}$ & $\begin{array}{l}+2.1 \pm 0.4 \\
-3.4 \pm 0.4\end{array}$ & $\begin{array}{l}-0.9 \pm 0.5 \\
-7.0 \pm 0.5\end{array}$ & & \multirow[t]{2}{*}{ Figure 10.} \\
\hline & Difference. & & $3.9 \pm 0.6$ & $5.5 \pm 0.6$ & $6.1 \pm 0.6$ & -.. & \\
\hline \multirow[t]{2}{*}{2} & $\begin{array}{l}21 \\
37\end{array}$ & $\begin{array}{r}15 \\
7\end{array}$ & $\begin{array}{l}-0.3 \pm 0.05 \\
-2.6 \pm 0.3\end{array}$ & $\begin{array}{l}+2.0 \pm 0.2 \\
-2.0 \pm 0.3\end{array}$ & $\begin{array}{l}-1.0 \pm 0.2 \\
-8.6 \pm 0.3\end{array}$ & $\begin{array}{r}-2.6 \pm 0.3 \\
-12.5 \pm 0.5\end{array}$ & \multirow[t]{2}{*}{$\begin{array}{l}\text { Figure } 11, \\
\text { curves } \mathrm{A} \text { and } \\
\mathrm{D} \text {. }\end{array}$} \\
\hline & Difference. . & & $2.3 \pm 0.3$ & $4.0 \pm 0.4$ & $7.6 \pm 0.4$ & $10.0 \pm 0.6$ & \\
\hline \multirow[t]{2}{*}{2} & $\left\{\begin{array}{c}21 \\
21 ; \text { changed to } 37\end{array}\right.$ & $\begin{array}{r}15 \\
4\end{array}$ & $-0.3 \underset{(\mathrm{e})}{ \pm} 0.05$ & $\begin{array}{l}+2.0 \pm 0.2 \\
+1.3 \pm 0.4\end{array}$ & $\begin{array}{l}-1.0 \pm 0.2 \\
-3.4 \pm 0.4\end{array}$ & & \multirow[t]{2}{*}{$\begin{array}{l}\text { Figure } 11, \text { curves } \\
\mathrm{A} \text { and } \mathrm{B} \text {. }\end{array}$} \\
\hline & Difference & & (n) & $0.7 \pm 0.5$ & $2.4 \pm 0.5$ & & \\
\hline \multirow[t]{2}{*}{2} & $\left\{\begin{array}{c}37 \\
37 ; \text { changed to } 21\end{array}\right.$ & $\begin{array}{l}7 \\
4\end{array}$ & $-2.6 \underset{(\mathrm{e})}{ \pm 0.3}$ & $\begin{array}{l}-2.0 \pm 0.3 \\
-1.7 \pm 0.4\end{array}$ & $\begin{array}{l}-8.6 \pm 0.3 \\
-4.6 \pm 0.4\end{array}$ & & \multirow[t]{4}{*}{$\begin{array}{c}\text { Figure } 11, \\
\text { curves C } \\
\text { and D. }\end{array}$} \\
\hline & Difference_.. & & (n) & $0.3 \pm 0.5$ & $4.0 \pm 0.6$ & - & \\
\hline \multirow[t]{2}{*}{ d 3} & $\begin{array}{l}21 \\
37\end{array}$ & $\begin{array}{r}10 \\
7\end{array}$ & $\begin{array}{l}-0.3 \pm 0.05 \\
-1.8 \pm 0.2\end{array}$ & $\begin{array}{l}+3.6 \pm 0.3 \\
+1.4 \pm 0.3\end{array}$ & $\begin{array}{l}+2.4 \pm 0.3 \\
-2.1 \pm 0.3\end{array}$ & $\begin{array}{l}+1.2 \pm 0.4 \\
-5.2 \pm 0.5\end{array}$ & \\
\hline & Difference _. & & $1.5 \pm 0.2$ & $2.2 \pm 0.4$ & $4.5 \pm 0.4$ & $6.4 \pm 0.6$ & \\
\hline
\end{tabular}

a Specimens prepared at $21^{\circ}$, unless otherwise noted.

a S4-day period, with fiducial observation 15 min after start of mix: $21^{\circ} \mathrm{C}$ gave an average of $-3.0 \pm 0.3 \mu / \mathrm{cm}, 37^{\circ} \mathrm{C}$ gave an average of $-9.9 \pm 0.3$, giving a difference of $6.9 \pm 0.4$

S Specimens prepared at $37^{\circ} \mathrm{C}$

dot comparable with alloys $i$ and 2 because of differences in alloy-mercury ratio and mixing time.

e Not observed. 
during the observation period (fig. 11 and table 2). Specimens held at $37^{\circ} \mathrm{C}$ and then subjected to a temperature decrease to $21^{\circ} \mathrm{C}$ shrank less than those maintained at $37^{\circ} \mathrm{C}$ (fig. 11 and table 2). Ag-Sn-Cu amalgams observed at $37^{\circ} \mathrm{C}$ also shrank more than those observed at $21^{\circ} \mathrm{C}$ (table 2 ).

Averages of the differences in dimensional changes of the $\mathrm{Ag}-\mathrm{Sn}(\mathrm{Cu}-\mathrm{Zn})$ amalgams at $21^{\circ}$ and $37^{\circ} \mathrm{C}$ are given in table 2 , together with their standard errors.

The standard error in each case depends on the number of specimens and on the precision of a single measurement. The latter was evaluated separately for each period of hardening, by pooling the variances, obtained for all amalgams, of the measurements made at that setting time.

In table 2 it is also shown that the fiducial observation (zero reading) taken $10 \mathrm{~min}$ after start of mix yielded a significantly lower expansion or greater contraction value over a $24-\mathrm{hr}$ period than the 15 -min fiducial observation. This variation results from the fact that a larger portion of the initial shrinkage is observed when the 10-min fiducial reading is used.

\section{Discussion of Results}

The observations of dimensional changes, along with the X-ray diffraction evidence that uncombined mercury is present in the amalgam, tend to substantiate the theory that the mechanism of dimensional change is associated with the presence of the uncombined mercury.

The following mechanism is postulated to explain the physical phenomena observed. The initial shrinkage always observed results from the formation of compounds of mercury and alloy having a smaller volume than the sum of the original volumes of the alloy and mercury. The subsequent expansion that is observed results from the diffusion into new areas of uncombined mercury entrapped in spaces throughout the amalgam. The reaction of this uncombined mercury with existing phases or with residual alloy to form compounds of lesser volume would then account for the contraction that follows the expansion of the amalgam.

This mechanism would account for the dimensional changes that occurred on the addition of mercury to hardened amalgam. When mercury is added to hardened amalgam the diffusion of this mercury throughout the specimen would produce the large expansion observed. The slight shrinkage observed immediately after the removal of the supply of mercury could result from the combination of free mercury in the specimen with existing phases or with residual alloy.
The greater shrinkage of amalgam mixed and maintained at $37^{\circ} \mathrm{C}$ rather than at $21^{\circ} \mathrm{C}$ may result from a more rapid chemical combination and disappearance of the uncombined mercury at elevated temperatures.

The proposed mechanism would also account for the shrinkage of amalgam that occurs from overtrituration or excessive working during condensation, in that either of these treatments would tend to reduce the amount of uncombined mercury by either furnishing new surfaces for reaction with the mercury or by actual mechanical removal of the mercury. These treatments would also tend to distribute the uncombined mercury present more uniformly throughout the amalgam so that there would be fewer mercury-rich areas from which dit"usion could take place. On the basis of this explanation, a reduction in size of the alloy particle or a heat treatment, which would make the partıcles more reactive, would tend to cause a reduced expansion or a shrinkage of the amalgam.

\section{Summary}

Residual, or uncombined, mercury has been demonstrated by X-ray diffraction studies to be present in amalgams after their initial solidification.

This uncombined mercury disappears during the period when greatest dimensional changes occur in the hardening of the amalgam system.

A possible mechanism for the dimensional changes, based on the presence and disappearance of the uncombined mercury, is presented.

\section{References}

[1] V. G. Black, Physical properties of silver-tin amalgams, Dental Cosmos 38, 965 (December 1896)

[2] W. A. Grav, Volume changes in amalgams, J. Inst. Metals 29, 139 (1923)

[3] Marie Gayler, The theory of the setting of dental amalgams, J. Brit. Dental Assoc. 60, 11 (July 1936).

[4] M. L. Ward, F. A. Peyton, and E. O. Scott, New concepts of mercury content in amalgams, J. Dental Research 16, 316 (August 1937).

[5] A. R. Troiana, An X-ray study of dental amalgams, J. Inst. Metals 58, 247 (1938).

[6] G. Ryge, J. C. Moffett, and A. G. Barlow, Microstructural observations and X-ray diffraction studies of silvertin amalgams, J. Dental Research 32, 152 (1953)

[7] D. L. Smith, G. W. Ferguson, and I. C. Schoonover, The microstructure of dental amalgam, J. Am. Dental Assoc. 47, 305 (September 1953).

[8] X-ray diffraction instrument and operating manual, North American Philips Corporation, Inc., Mt. Vernon, N. Y

[9] Wilmer Souder and G. C. Paffenbarger, Physical properties of dental materials, NBS Circular 433 (1942).

Washington, October 30, 1953. 